\title{
Spondylodiscitis, an Exceptional Complication of Prostate Biopsy: Case Report
}

\author{
Abd el Kader Moumouni1 ${ }^{*}$, Tchilabalo Matchonna Kpatcha², Massaga Dagbe ${ }^{3}$, \\ Katanga Anthony Beketi',4, Mawouto Akpalou', Gnimdou Botcho², Komi Hola Sikpa², \\ Detema Wenkouda Maba6 ${ }^{6}$, Fabie Opeku${ }^{1}$, Komi Awume ${ }^{1}$, Bidamin Ntimon ${ }^{3}$, Tchin Darre ${ }^{7}$ \\ ${ }^{1}$ Neurosurgery Department, University Teaching Hospital of Kara, Kara, Togo \\ ${ }^{2}$ Urology Department, University Teaching Hospital of Kara, Kara, Togo \\ ${ }^{3}$ Radiology Department, University Teaching Hospital of Kara, Kara, Togo \\ ${ }^{4}$ Neurosurgery Department, Sylvanus Olympio Teaching Hospital, Lomé, Togo \\ ${ }^{5}$ Surgery Department, CHR Atakpamé, Atakpamé, Togo \\ ${ }^{6}$ Bacteriology Laboratory, University Teaching Hospital of Kara, Kara, Togo \\ ${ }^{7}$ Pathologyanatomy Laboratory, Sylvanus Olympio Teaching Hospital, Lomé, Togo \\ Email: *makmas2003@yahoo.fr, fakpatcha@yahoo.fr
}

How to cite this paper: Moumouni, A. el K., Kpatcha, T.M., Dagbe, M., Beketi, K.A., Akpalou, M., Botcho, G., Sikpa, K.H., Maba, D.W., Opeku, F., Awume, K., Ntimon, B. and Darre, T. (2021) Spondylodiscitis, an Exceptional Complication of Prostate Biopsy: Case Report. Open Journal of Modern Neurosurgery, 11, 97-101. https://doi.org/10.4236/ojmn.2021.112011

Received: March 1, 2021

Accepted: April 24, 2021

Published: April 27, 2021

Copyright $\odot 2021$ by author(s) and Scientific Research Publishing Inc. This work is licensed under the Creative Commons Attribution International License (CC BY 4.0).

http://creativecommons.org/licenses/by/4.0/ (c) (i) Open Access

\begin{abstract}
Background: Transrectal prostate biopsy is a major prostate cancer diagnosis procedure that can cause infectious complications. Osteoarticular localization is uncommon. Aim: To report a case of spondylodiscitis due to a transrectal prostate biopsy and highlight therapeutical principles. Case Presentation: A 60-year-old male underwent transrectal prostate biopsy performed because of high PSA level, and presented 48 hours later with back pain, fever at $40^{\circ} \mathrm{C}$ associated with an obnubilation. He was treated for malaria without favorable evolution. Persistance of pain and occurrence of neurologic manifestations motivated dorso-lumbar Computed Tomography (CT) and Magnetic Resonance Imaging (MRI) which permitted diagnosis of spondylodiscitis. The treatment was made by triple antibiotic therapy combining Imipenem 500 mg/8h (IV); Ofloxacin $200 \mathrm{mg} / 12 \mathrm{~h}$ (IV) and Metronidazole $500 \mathrm{mg} / 8 \mathrm{~h}$ (IV) over four weeks. Evolution under treatment was favorable. Conclusion: Spondylodiscitis is an exceptional complication of transrectal prostate biopsy. It may be evocated in case of bones pain after prostate biopsy.
\end{abstract}

\section{Keywords}

Spondylodiscitis, Prostate Biopsy, Complication

\section{Introduction}

Transrectal prostate biopsy is a major diagnostic procedure of prostate cancer 
that it can be associated with severe complications. Infectious complications are among the most frequent, occurring in $2 \%-4 \%$ of patients [1]. In our context, they are usually caused by Escherichia colii [2]. Resistance to fluoroquinolone has been reported as one of the factors associated to increasing infection occurring after prostate biopsy [3]. Although some cases have been reported in the literature, the osteo-articular localization is exceptional but can have life-threatening consequences [4]. We report the case of an immunocompetent patient presented with spondylodiscitis following transrectal prostate biopsy.

\section{Case Report}

A 60-year-old patient consulted for an elevation of the prostate specific antigen (PSA) rate of $13 \mathrm{ng} / \mathrm{ml}$. He had no mictional disorder and no urological history. He had no personal or family history of genetic disease and was not taking any immunosuppressive therapy. The initial examination revealed a prostate with increased volume, with normal consistency and a smooth surface. The results of the suprapubic prostatic ultrasound were as follows: prostatic gland of $45 \mathrm{ml}$ volume, homogeneous appearance. The patient underwent transrectal prostatic biopsy (12 cores) with local anesthesia, preceded by a single dose of ciprofloxacin $500 \mathrm{mg}$ and a rectal hypertonic enema. The result of histologic analysis was benign prostatic hyperplasia (Figure 1). Forty-eight (48) hours later there was a fever at $40^{\circ} \mathrm{C}$ associated with an obnubilation and shiver. Biological parameters were as follow: white blood cell (WBC) count of $18,000 / \mu$ l, C-reactive protein (CRP) $25 \mathrm{mg} / \mathrm{l}$, creatinine $13 \mathrm{mg} / \mathrm{l}$, azotemia $0.43 \mathrm{~g} / \mathrm{l}$, glycemia $0.98 \mathrm{~g} / \mathrm{l}$. The diagnosis of malaria has been retained and the patient was treated in a non-specialized medical establishment with arthemeter for 72 hours. A specialized advice helped to rectify the diagnosis of acute prostatitis with regard to the persistence of fever. The evolution under probabilistic antibiotic therapy (Ceftriaxone $2 \mathrm{~g} / 24 \mathrm{~h}$ and Gentamicin $160 \mathrm{mg} / 24 \mathrm{~h}$ ) was marked by occurrence of intense and disabling low back pain not yielding under analgesics of steps 1 and 2 with the occurrence of paraparesis. The radiography of the vertebral skeleton and pelvis performed prematurely showed no lesions. Dorso-lumbar Computed Tomography (CT) made it possible to diagnose spondylodiscitis (Figure 2(a)).

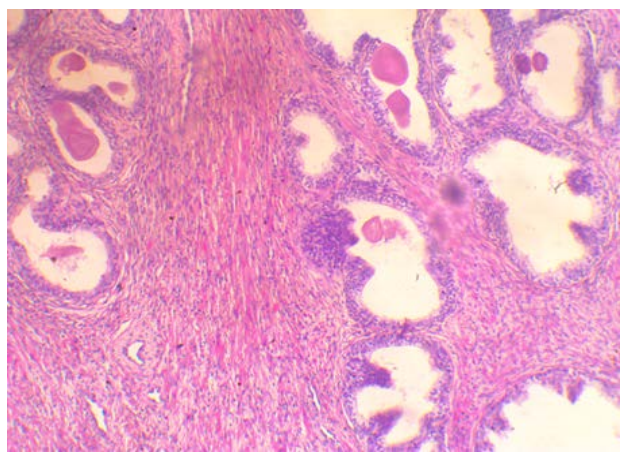

Figure 1. Prostate histologic analysis: rounded concretion with lamellar appearance and calcified, surrounded by a smooth hyperpmasic muscle tissue. 


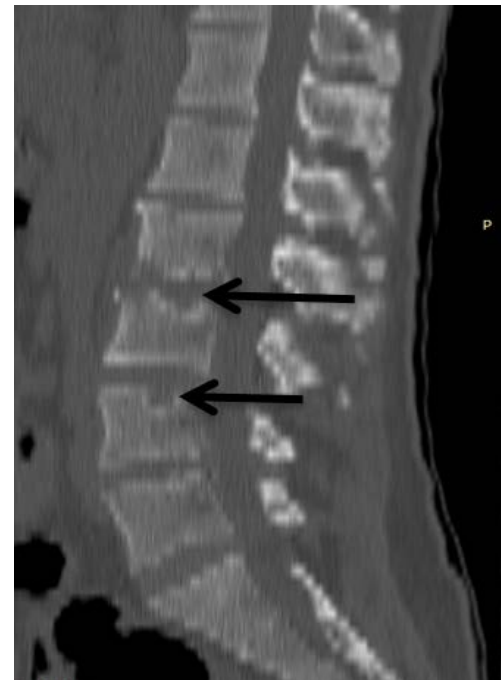

(a)

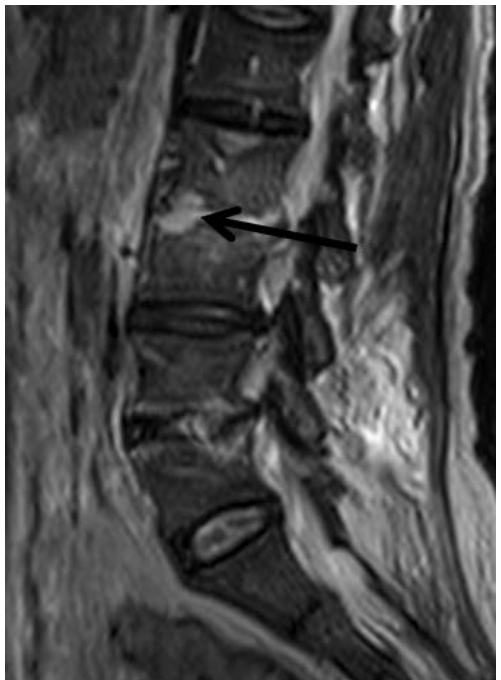

(b)

Figure 2. Dorso-lumbar Computed Tomography (CT) (a) and dorso-lumbar Magnetic Resonance Imaging (MRI) (b). (a): osteolytic lesions of the 3rd, 4th and 5th lumbar vertebrae on MRI (sagittal view); (b): osteolytic lesions of the 3rd, 4th and 5th lumbar vertebrae on CT (sagittal view).

A dorso-lumbar Magnetic Resonance Imaging (MRI) was made in order to make a more accurate lesion assessment (Figure 2(b)). The search for a causative agent through urinary and blood tests was negative; the spinal tap test was not performed. Triple antibiotic therapy combining Imipenem $500 \mathrm{mg} / 8 \mathrm{~h}$ (IV); Ofloxacin $200 \mathrm{mg} / 12 \mathrm{~h}$ (IV) and Metronidazole $500 \mathrm{mg} / 8 \mathrm{~h}$ (IV) over four weeks allowed a gradual resumption of mobility, the disappearance of pain, and the improvement of the infectious syndrome. The patient had fully recovered after six months. At functional level, the mobility was totally recovered but with a mild spinal pain.

\section{Discussion}

The risks of prostatic biopsy evolve a diagnosis procedure that must be prepared and performed under the best conditions of asepsis to minimize complications. These complications are mostly infectious and usually limited to the urogenital tract if taken care early and appropriately. The diagnostic and adequate treatment delay of the post-biopsic infection in our patient explains the secondary localization to the osteo-articular tissue. The correlation between bone pain and infectious bone disease is not evident in urological context. The diagnostic error is also linked to the easy diagnosis of malaria in case of any fever associated with aches in our malaria endemic area.

In the literature, secondary osteo-articular complications to prostatic biopsy are rare, probably because of the precautions surrounding this procedure [5]. Antibiotic prophylaxis does not guarantee the absence of infection even if it significantly reduces the rate and severity, and some studies have shown that more than half of post-biopsy infections are resistant to fluoroquinolone [6]. Targeted 
antimicrobial prophylaxis with pre-biopsy rectal culture has been described as an efficient prevention procedure, reducing significantly the rate of infectious complications associated with transrectal prostate biopsy [7].

The management of spondylodiscitis combines antibiotic therapy and immobilization, which not only relieves pain but also avoids the complications associated with the weakening of the osteo-articular structures. The collaboration between the urologist, neurosurgeon and infectiologist is a guarantee of a successful treatment.

Therapeutic indications take into account five key elements: the infectious agent, the instability of the segment, the presence of abscess, neurological impairment, and infectious outbreak [8].

The most frequent infectious outbreak is certainly lumbosacral because of its rich vascularization and the direct vascular connection between venous drainage of both the prostate and lumbar vertebrae, but also its mobility which creates a "pump effect" [9] [10]. Frequent involvement of this segment explains the frequently noticed instability, and which requires stabilization surgery in $83.9 \%$; whereas spinal cord compressions are more frequent at the cervical spine [10].

A conservative method consisting of local infiltration of antibiotic for three cycles of three weeks separated by five weeks each was tested by some authors [11]. Although its effectiveness has not been formally proven, it could allow a faster functional recovery than the standard treatment.

\section{Conclusion}

This case recalls the need for an appropriate and early management of prostatitis after a prostate biopsy. Disabling osteo-articular pain associated with fever could be a reminder of bone infection in the aftermath of a prostatic biopsy.

\section{Ethics Approval}

This case report was approved by the Department of Urology of CHU Kara, University of Kara.

\section{Consent}

Written informed consent was obtained from the patient for publication of this case.

\section{Guarantor}

Tchilabalo Matchonna Kpatcha is the guarantor of this work.

\section{Conflicts of Interest}

The authors declare no conflicts of interest regarding the publication of this paper.

\section{References}

[1] Zani, E.L., Clark, O.A. and Rodrigues Netto, N. (2011) Antibiotic Prophylaxis for 
Transrectal Prostate Biopsy. Cochrane Database of Systematic Reviews, 5, Article ID: CD006576. https://doi.org/10.1002/14651858.CD006576.pub2

[2] Kpatcha, T.M., Darré, T., Padja, E., Leloua, A.E., Botcho, G., Sewa, E.V., et al. (2018) Prostate Biopsy: Which Technique for Which Results at Lomé University Hospital in 2017? Open Journal of Urology, 8, 125-133.

https://doi.org/10.4236/oju.2018.84014

[3] Rudzinski, J.K. and Kawakami, J. (2014) Incidence of Infectious Complications Following Transrectal Ultrasound-Guided Prostate Biopsy in Calgary, Alberta, Canada: A Retrospective Population-Based Analysis. Canadian Urological Association Journal, 8, E301-E305. https://doi.org/10.5489/cuaj.1751

[4] Li, C.C., Li, C.Z., Wu, S.T., Chat, T.L. and Tang, S.H. (2017) Spondylodiscitis with Epidural and Psoas Muscle Abscesses as Complications after Transrectal Ultrasound-Guided Prostate Biopsy: Report of a Rare Case. European Journal of Case Reports in Internal Medicine, 4. https://doi.org/10.12890/2017_000694

[5] Lechevallier, E. (1996) Prostate Biopsy. Progrès en Urologie, 6, 507-518.

[6] Zaytoun, O.M., Vargo, E.H., Rajan, R., Berglund, R., Gordon, S. and Jones, J.S. (2011) Emergence of Fluoroquinolone-Resistant Escherichia coli as Cause of Postprostate Biopsy Infection: Implications for Prophylaxis and Treatment. Urology, 77, 1035-1041. https://doi.org/10.1016/j.urology.2010.12.067

[7] Taylor, A.K., Zembower, T.R., Nadler, R.B., Scheetz, M.H., Cashy, J.P., Bowen, D., Murphy, A.B., Dielubanza, E. and Schaeffer, A.J. (2012) Targeted Antimicrobial Prophylaxis Using Rectal Swab Cultures in Men Undergoing Transrectal Ultrasound Guided Prostate Biopsy Is Associated with Reduced Incidence of Postoperative Infectious Complications and Cost of Care. Journal of Urology, 187, 1275-1279. https://doi.org/10.1016/j.juro.2011.11.115

[8] Berbari, E.F., Kanj, S.S., Kowalski, T.J., Darouiche, R.O., Widmer, A.F., Schmitt, S.K., et al. (2015) Infectious Diseases Society of America (IDSA) Clinical Practice Guidelines for the Diagnosis and Treatment of Native Vertebral Osteomyelitisin Adults. Clinical Infectious Diseases, 61, e26-46. https://doi.org/10.1093/cid/civ482

[9] Dobson, G., Cowie, C.J.A. and Holliman, D. (2015) Epidural Abscess with Associated Spondylodiscitis Following Prostatic Biopsy. Annals of the Royal College of Surgeons of England, 97, e81-e82. https://doi.org/10.1308/003588415X14181254790563

[10] Gentile, I., Benazzo, F., de Rosa, F., Boriani, S., Dallagiacoma, G., Franceschetti, G., et al. (2019) A Systematic Review: Characteristics, Complications and Treatment of Spondylodiscitis. European Review for Medical and Pharmacological Sciences, 23, 117-128.

[11] Bonura, E.M., Morales, D.J.O., Fenga, D., Rollo, G., Meccariello, L., Leonetti, D., et al. (2019) Conservative Treatment of Spondylodiscitis: Possible Therapeutic Solution in Case of Failure of Standard Therapy. Medical Archives, 73, 39-43. https://doi.org/10.5455/medarh.2019.73.39-43 